\title{
Katholischer Medienpreis 2005
}

\section{Kategorie Print}

Auf Vorschlag der Jury zeichnete die Deutsche Bischofskonferenz mit dem Katholischen Medienpreis 2005 hier den Beitrag von Wolfgang Uchatius: Das globalisierte Dienstmädchen (erschienen in der Wochenzeitschrift "Die Zeit" Nr. 35 vom 19. August 2004) aus.

Der Autor Wolfgang Uchatius (geb. 1970) ist Wirtschaftsredakteur bei der „Zeit“.

\section{Zum Inhalt:}

Wolfgang Uchatius lenkt den Blick der Öffentlichkeit auf eine bisher kaum beachtete Seite der Globalisierung. Am Beispiel von Lydia Flores aus einer Stadt 100 Kilometer südlich von Manila zeichnet er das Schicksal gebildeter philippinischer Frauen nach, die sich in Deutschland und anderen wohlhabenden Industriestaaten als Haushaltshilfen verdingen, um ihren Kindern zu Hause ein Leben in Würde zu ermöglichen, und die dabei, manchmal zusammen mit ihren Ehemännern, das schwere Los der Illegalität auf sich nehmen.

\section{Preisbegründung:}

Dem Autor gelingt es in dichter Reportagesprache, ergänzt durch sozialwissenschaftliche Beobachtungen, das Schizophrene der Situation zu erzählen: Einerseits sind diese Frauen im Gastland hochwillkommen, gutsituierte Familien reißen sich um sie, andererseits trauen sie sich aus Angst, wegen fehlender Arbeitspapiere abgeschoben zu werden, kaum aus dem Haus ihrer Arbeitgeber. Wolfgang Uchatius verbindet seine einfühlsame Beschreibung des Lebens der Migrantinnen mit einer profunden Darstellung der Zustände in deren Heimat: Während die Frauen sich in der Fremde um die Babys anderer Leute kümmern, wächst auf den Philippinen inzwischen fast jedes dritte Mädchen, jeder dritte Junge ohne Mutter, Vater oder ganz ohne Eltern auf - diese schicken Geld, sie rufen an, aber sie bleiben für den eigenen Nachwuchs unsichtbar. Mit Nachdruck stellt der Verfasser die Frage nach der Zukunft einer solchen Gesellschaft, in der bislang die Familie als Kern privaten Glücks galt. Mit seinem Beitrag über die „Handy-Eltern“, beziehungsweise die „Feminisierung der Migration“, bei der sich auf seltsame Weise feudale Vergangenheit und emanzipatorische Gegenwart vermischen, erfüllt Wolf- 
gang Uchatius geradezu exemplarisch Zielsetzungen des Katholischen Medienpreises, das Verständnis für Menschen und gesellschaftliche Zusammenhänge zu fördern sowie das humanitäre und soziale Verantwortungsbewusstsein zu stärken.

\section{Kategorie elektronische Medien}

Hier zeichnete die Deutsche Bischofskonferenz

den Fernsehfilm von Max Kronawitter: „Streit mit Gott - Ein Pfarrer im Rollstuhl" aus (Kamera: Rupert Heilgemeir, Schnitt: Birgit Thieme, Redaktion: Andrea Kammhuber), der vom Bayerischen Rundfunk in der Sendereihe "Stationen" am 30. Juni 2004 ausgestrahlt wurde.

Der Autor Max Kronawitter (geb. 1962) ist Theologe, Filmautor und Regisseur.

\section{Der Inhalt:}

Der Priester Michael Mayer hat eine schillernde Geschichte: Studium in Rom, Promotion, Herausgeber einer kirchlichen Jugendzeitschrift, Aktivist in der Friedensbewegung, dann Gemeindepfarrer in Augsburg. Die Kirche, für die er Priester wurde, sollte - davon war er überzeugt - Licht für die Menschen, ein erfahrbares Zeugnis eines anwesenden Gottes sein. 1983 dann der Einbruch: Eine Virusinfektion führt zu einer Lähmung, an der er fast stirbt. Für einige Zeit sogar erblindet er.

Die Hilflosigkeit, der Kontrollverlust über seinen Körper, der ihm nun wie ein Fremd-Körper erscheint, all das beschämt und lässt ihn verzweifeln. Der Pfarrer Mayer hadert heftig mit seinem Gott, wenn er sagt: "Gott tut was er will - hoffentlich weiß er, was er tut". Heiliger Zorn befällt ihn bei frommen, aber inhaltsleeren Sprüchen der Menschen, die eigentlich "mit dem Kreuz vertraut sind" und ihm sein Leid erklären möchten.

Die Gemeinde lässt ihn in dieser Zeit nicht fallen. Das Leben des einst eigentlich hoch gewachsenen Michael Mayers von da an im Rollstuhl zwingt ihn in die Perspektive von Kindern. Eine Etage, so sagt er, sei er zwar tiefer gerutscht. Dennoch entdeckt er dort das Leben neu. Er begreift, dass eine Antwort auf das Warum des Leides kaum $z \mathfrak{u}$ finden ist. Mayer erfährt dagegen die Kraft, die Menschen in gemeindlicher Gemeinschaft entwickeln können, an der er innerlich „auf(er)steht“.

In der Krankenhausseelsorge findet er eine neue Aufgabe. Als Behinderter unter Kranken ist seine Seelsorge erfahrungsgetränkter, noch menschendienlicher geworden. Er ist ein gesuchter Ansprechpartner, sowohl für die Kranken, als auch für die Gesunden. 
Die Preisbegründung:

Max Kronawitter erzählt mit seinem Film „Streit mit Gott - Ein Pfarrer im Rollstuhl“ die Geschichte einer Theodizee-Erfahrung."Er geht also der alten Frage nach, warum Gott Leid zulässt. Filmisch eindrucksvoll zeigt er einen existentiellen und religiösen Zusammenbruch eines Menschen. Das erinnert an Hiob: Da steht einer vor dem Nichts.

Der Priester sucht sprachliche Formen und Bilder, die ihm helfen, sich selbst wenigstens zum Ausdruck bringen zu können. Das „in Wörtern wohnen zu können“ sind die ersten "Schritte“ vom „Fremd-KörperDasein" zur neuen Einheit mit sich und letztlich mit Gott.

Max Kronawitter hat sich mit seinem sehr einfühlsamen, bildlich oft symbolstarken und auf der Tonebene durchaus akzentuierten Film an wichtige Themen gewagt, die in den Zwischen-Zeiten von Spaß-Gesellschaft und deren Verhärtung viele betreffen.

Er blickt ins Dunkel des Menschlichen, um dann der Plausibilität von Transzendenz nachzuspüren. Der Erfahrung des existentiellen Abgrunds setzt er nicht spirituelles Fast-Food entgegen, sondern entdeckt Inkarnationen des Christlichen. Ein Wagnis ist der Film deshalb, weil Kronawitter nicht mit journalistisch-professioneller Distanz eine Geschichte "baut", um sich dann persönlich aus dem Staub zu machen, sondern damit dem Zuschauer sagt: „Schaut her, davon bin ich überzeugt". Ist das anschlussfähig? Auf jeden Fall ist es ein flammendes Plädoyer für eine christlich-authentische, für eine menschendienliche Kommunikationskultur.

Die Jury des Katholischen Medienpreises hält dieses filmische Credo zwischen den zeitgeistlichen Fronten diskursethischen Allerleis einerseits und Fremdbestimmung jeglicher Provenienz andererseits für herausragend, weil es sich tief in das Verstehen des Menschen einlässt, die Kommunikation „geliehener Worte“, also biblischer Traditionen fördert sowie christlicher Werte plausibel macht. Wie sagt es Hiob am Ende? „Vom Hörensagen nur hatte ich von dir vernommen; jetzt aber hat mein Auge dich geschaut." 